\title{
Editorial to: "Building a Bridge to the Future of Cardiovascular Drugs and Therapy"
}

\author{
Sean M Davidson ${ }^{1}$
}

Published online: 13 February 2017

(C) Springer Science+Business Media New York 2017

In 1987, some 30 years ago, the journal Cardiovascular Drugs and Therapy was founded by two eminent cardiologists, Henry N. Neufeld and Lionel H. Opie. It was initially sponsored by the International Society for Cardiovascular Pharmacotherapy with the aim of promoting world-wide research and development. The Journal was formed in response to the need to bridge the gap between the pharmaceutical industries and academic and practicing cardiologists. The recognition of this need turned out to be highly prescient, as communication between these groups remains crucial to the development of new cardiovascular drugs and therapies today.

The Journal was founded at an exciting time in cardiovascular medicine, when the development of acute coronary care and noninvasive diagnostic methods for earlier disease detection were leading to a decline in mortality from coronary heart disease for the first time. Reassuringly, these trends have continued. At that time, cardiovascular disease was recognized as the primary cause of death in Western societies. Since then, however, the disease has become no longer the preserve of the affluent West, and remains the number one killer globally. This highlights the need for revolutionary new approaches to treating cardiovascular disease.

Looking back at the very first issue of Cardiovascular Drugs and Therapy it is notable that it included a focussed section on ACE inhibitors [1]. The first ACE inhibitor had been isolated from the venom of the Brazilian pit viper Bothrops jararaca about 10 years previously, and small mol-

Sean M Davidson

s.davidson@ucl.ac.uk

1 The Hatter Cardiovascular Institute, University College London, WC1E 6HX, London, UK ecule inhibitors subsequently designed by a process of rational design. Inhibition of the renin-angiotensin pathway remains one of the cornerstones of cardiovascular medicine, as outlined by recent reviews including those appearing within in this Journal [2]. Interestingly, LCZ696 (Valsartan plus sacubitril), one of the newest cardiovascular drugs of the current era [3], in addition to inhibiting the enzyme neprilysin targets the same angiotensin pathway.

The phenomenon of ischaemic preconditioning was discovered is 1987 , the same year as the Journal was founded, and the two have evolved continuously and in parallel ever since. In this issue, one of the leading researchers in this area, Robert Kloner takes a step back to look at recent progress in this important area, and the exciting new directions with the most potential for moving this field forward [4].

As populations grow, and environmental effects such as diet, smoking frequency and air pollution evolve, the spectrum and presentation of cardiovascular diseases varies. It is increasingly evident that, despite the impressive benefits of emerging cancer therapies, a substantial proportion of today's successfully-treated cancer patients may become tomorrow's cardiac patient. The group of Prof Derek Yellon of the Hatter Cardiovascular Institute in London, reviews the mechanism of anthracycline cardiotoxicity, and potential methods being developed in order to protect against this injury [5]. This group also offer a review of the topic of cardioprotection in relation to exosomes, endogenous nanoparticles which had only recently been named at the time the Journal began, but which have seen a monumental explosion of interest in recent years [6].

Thirty years ago mitochondria were primarily regarded purely from the point of view of ATP generation. They are now known to play a central role in cellular survival, and cardiac health and disease, and understanding how their shape and activity is regulated has become a question of major 
importance. Derek Hausenloy and co-workers examine this rapidly evolving field in their review [7].

Protein quality control is increasingly recognized as critical in maintaining cellular homeostasis and function. Recent evidence suggests it may be a causal mechanism for the development of atherosclerosis and heart failure. Minamino et al. review the mechanisms of protein quality control and how they may be involved in cardiovascular complications induced not only by anthracyclines, but also by anti-cancer drugs such as tyrosine kinase inhibitors and proteasome inhibitors [8].

It is hoped that this selection of reviews on key topics illustrates the progress that has been made in cardiovascular research over the past 30 years, and the new areas opening up as a consequence both of changing landscape of disease, and revolutions in research.

\section{Compliance with Ethical Standards}

Conflict of Interest S Davidson declares that he has no conflict of interest.

Ethical Approval This article does not contain any studies with human participants or animals performed by any of the authors.

\section{References}

1. Chatterjee K, Opie LH. Angiotensin inhibitors and other vasodilators with special reference to congestive heart failure. Cardiovasc Drugs Ther. 1987;1(1):1-8.

2. von Lueder TG, Krum H. RAAS inhibitors and cardiovascular protection in large scale trials. Cardiovasc Drugs Ther. 2013;27(2):171-9.

3. Lin LM, Wu Y, Wu MF, Lin JX. Focus on the novel cardiovascular drug LZC696: from evidence to clinical consideration. Cardiovasc Drugs Ther. 2016;30(6):623-33.

4. Kloner RA, Hale SL, Dai W, Shi J. Cardioprotection: where to from here? Cardiovasc Drugs Ther. 2017;31, this issue.

5. McGowan JV, Chung R, Maulik A, Piotrowska I, Walker JM, Yellon DM. Anthracycline chemotherapy and cardiotoxicity. Cardiovasc Drugs Ther. 2017;31, this issue.

6. Davidson SM, Takov K, Yellon DM. Exosomes and cardiovascular protection. Cardiovasc Drugs Ther. 2017;31, this issue.

7. Ong S-B, Khalkoran SB, Hernandez-Resendiz S, Samangouei P, Ong S-G, Hausenloy DJ. Mitochondrial-shaping proteins in cardiac health and disease - the long and the short of it! Cardiovasc Drugs Ther. 2017;31, this issue.

8. Minamino T, Fu HY, Mukai M, Awata N, Hori M. Protein quality control disorders as new therapeutic targets in cardiovascular complications induced by anti-cancer drugs. Cardiovasc Drugs Ther. $2017 ; 31$, this issue. 